\title{
Successful Use of eProcurement in Supply Chains
}

\author{
Thomas Puschmann \\ The Information Management Group (IMG AG), St.Gallen \\ thomas.puschmann@img.com \\ Rainer Alt \\ Institute of Information Management, University of St.Gallen \\ rainer.alt@unisg.ch
}

\begin{abstract}
Optimizing the internal supply chain for direct or production goods was a major element during the implementation of enterprise resource planning systems (ERP) which has taken place since the late 1980s. However, supply chains to the suppliers of indirect materials were not usually included due to low transaction volumes, low product values and low strategic importance of these goods. With the advent of the Internet, systems for streamlining indirect goods supply chains emerged and were adopted by many companies. In view of the paperprone processes in many companies, the implementation of these electronic procurement systems led to substantial improvement potentials.

This research reports the quantitative and qualitative results of a benchmarking study which explores the use of the Internet in procurement (eProcurement). Among the major goals are to obtain more insight on how European and North American companies used and introduced eProcurement solutions as well as how these systems enhanced the procurement function. The analysis presents a heterogeneous picture and shows that all analyzed solutions emphasize different parts of the procurement and coordination process. Based on interviews and case studies the research proposes an initial set of generalized success factors which may improve future implementations and stimulate further success factor research.
\end{abstract}




\section{Introduction}

\subsection{Evolution of eProcurement}

As a major part of supply chain management (Leenders and Fearon, 1997; Monczka et al., 1997), supply chains in procurement are traditionally supported by information technology. With the implementation of ERP or MRP systems in the 1980s EDI connections with suppliers were established. For example, close partnerships have been forged with direct material suppliers through the automation of delivery schedules by linking a company's materials management system with supplier systems. Since the mid 1990s companies have also been redesigning their relationships with business partners for indirect procurement. Direct procurement addresses all components and raw materials that are used in the manufacturing process of a finished product, such as sheet metal, semiconductors, and petrochemicals (Lamming, 1995), whereas indirect procurement relates to products and services for maintenance, repair and operations (MRO) and focuses on products and services that are neither part of the end product nor resold directly (Zenz, 1994). Traditionally, ERP systems have been applied to products with high transaction volumes and direct implications for value-adding processes. As a consequence, we still find paper-prone and labor-intensive processes for indirect procurement which harbor large inefficiencies.

The diffusion of eProcurement systems in the late 1990s has created the potential for reorganizing the MRO supply chains. Compared to ERP, these systems were considerably less expensive and more flexible due to increased standardization on a technical level. More or less all studies on eProcurement report large efficiencies regarding process and procurement costs (Gebauer and Segev, 1998). The main idea of eProcurement is to include the end-user (requester) in the procurement process via an electronic multi-vendor catalog and to close the process gaps (e.g. re-entry of data) in the supply chain for indirect goods (Neef, 2001). A third phase of development in eProcurement has also been observable with the integration of electronic markets (eMarkets) in the supply chain since the end of the 1990s (Poirier and Bauer, 2000). These eMarkets evolved alongside the early system vendors like Ariba, Commerce One or SAP and support the outsourcing of operational procurement functions, offering tools for auctions and requests for quotations. However, the following evolution of eMarkets has led to a substantial consolidation and many now focus on outsourced solutions for catalogs and auctions.

To summarize, these three development stages form the basis for the term eProcurement in this paper. According to (Dolmetsch et al., 2000), eProcurement deals with the management of supply chains in the procurement of indirect goods which is based on Internet information systems and also eMarkets.

\subsection{Benefits of eProcurement}

The potentials of eProcurement have already been proven in a number of studies (Aberdeen, 2001; Eyholzer and Hunziker, 2000; Andersen, 2001). According to these studies, eProcurement enables companies to decentralize operational procurement processes and centralize strategic procurement processes as a result of the higher supply chain transparency provided by eProcurement systems.

Typically, a company's procurement function is subdivided into strategic and operational processes since activities and priorities in these two areas are entirely different (Kaufmann, 
1999; Lamming, 1995). Supplier management, the pooling of purchase requisitions and procurement-oriented product development are tasks which are typically assigned to strategic procurement. Prior to eProcurement, strategic procurement often had to deal with administrative routine work as well, such as individual transactions, converting purchase requests into purchase orders or ensuring the correct allocation of invoices received. Strategic aspects are frequently neglected in the process, with the buyer having little influence over the choice of suppliers and the purchased products. The use of Internet technologies in procurement is aimed at realizing faster and more efficient operational procurement processes which bypass the purchasing department and enable those people to concentrate on more strategic tasks (Giunipero and Sawchuk, 2000; see Figure 1). In eProcurement, requesters directly search for and select products in electronic catalogs which are authorized and negotiated by strategic procurement in advance.

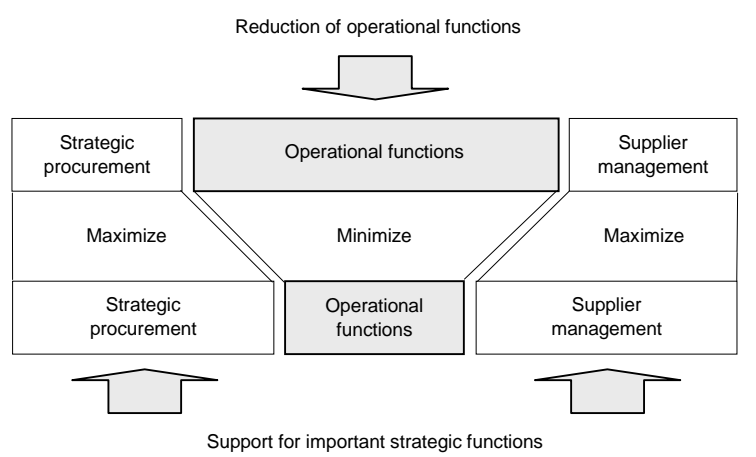

Figure 1. Effects of eProcurement

\subsection{Successful use of eProcurement}

Despite the potentials promised by the vendors of such systems, eProcurement got off to a slow start. A study by (Eyholzer and Hunziker, 2000) shows that only 18 percent of the Swiss companies analyzed used electronic product catalogs, auctions or requests for quotations in procurement in the year 2000. According to this study, however, many companies were planning to implement eProcurement systems at that time. Other studies show similar proportions for other countries (e.g. Industrial Distribution, 2001 and Administration, 2000 for the USA). A study by (Wyld, 2004) reports that currently almost half of all American companies use eProcurement systems.

Although the adoption of eProcurement has rapidly increased in recent years, companies face different challenges associated with the advent and use of eProcurement. One is that most companies only apply single eProcurement functions. The analysis by (Wyld, 2004) shows that in the US only $30 \%$ of the companies surveyed use eProcurement systems for requests for quotations, online auctions $(25 \%)$ or eMarkets $(33 \%)$. A second challenge is that, despite the overwhelming evidence which shows the advantages of eProcurement systems, proprietary systems such as electronic data interchange (EDI) continue to persist, and have to be included in a company's overall eProcurement infrastructure. To do so, companies need to know the critical success factors in implementing eProcurement strategies, processes and systems.

From an academic perspective, some initial contributions to success factor research exist. An analogy with the natural sciences shows that causal links between actions and their successful effects as the main goal. In the social sciences, the deterministic claim of the empirical success factor research approach very often cannot contribute clear results (e.g. Eyholzer and Hunziker, 2000; Industrial Distribution, 2001; Administration, 2000; Wyld, 2004, Kauffmann 
and Mohtadi, 2004; Gebauer and Shaw, 2004). Instead of the verification of constant laws, the search for a few parameters (success factors) is therefore proposed (e.g. Boynton and Zmud 1984). This more qualitative research approach identifies success factors from case studies and differs from empirical success factor research which defines strong requirements in terms of validity and reliability. Despite these missing causal effects, there is a belief that research has to strive for recommendations that reduce uncertainty and guide management actions (Tan and Pan, 2002).

Because of the difficulties of empirical success factor research, this article chooses a two-part qualitative approach. It summarizes the results of a benchmarking study which was conducted by a consortium of 12 multi-national companies from Germany and Switzerland. During the benchmarking process which took place between March and September 2000, 120 questionnaires were distributed, 10 telephone interviews were conducted, and finally five successful practice companies were selected and analyzed in detail. The article analyzes implemented eProcurement solutions and identifies factors which the companies surveyed cited as important requirements for the successful use of eProcurement systems in their organizations.

\section{Research method}

\subsection{Benchmarking method}

Benchmarking can be defined as the systematic comparison and learning from other companies with the goal of achieving sustainable improvements for a company's own position (Camp, 1989). Depending on focus, two benchmarking approaches can be distinguished which are not mutually exclusive (Pieske, 1995):

- Goal of comparison: Quantitative benchmarking is aimed at comparing efficiency on the basis of key performance indicators in order to define a company's position by applying objective criteria. The goal of qualitative benchmarking, on the other hand, is to deduce reference concepts, methods and models for the design and the transfer of successful practices to one's own company.

- Horizon of comparison: Four main types of benchmarking can be differentiated depending on organizational focus. Internal benchmarking studies allow companies to compare best practices on a quantitative, key performance indicator-based approach. External methods such as competitive benchmarking support individual positioning very well but are lacking when it comes to discovering detailed key performance indicators from other industries (Boutellier et al., 1999).

The consortium benchmarking which was applied for this benchmarking project concentrates on an external, industry-independent comparison of generic concepts and critical success factors. The company consortium consisted of purchasing specialists from twelve German and Swiss companies and was supported by an expert team consisting of the University of St.Gallen's Institute of Information Management and its Benchmarking Center TECTEM. The consortium benchmarking method aims to identify cross-industry successful practices which are selected in a given project procedure. These successful practices are concepts, methods and models which have been proven in one or more companies and lead to a competitive advantage (Boutellier et al., 1999). 
Qualitative benchmarking requires the definition of objects of comparison to ensure the comparability of the successful practices (Camp, 1989). In the eProcurement benchmarking project, these objects were defined during the first consortium meeting. The objects of comparison were: introduction project, the procurement organization, content and catalog management, supply chain processes and system architecture, as well as operational efficiency (see Figure 2).

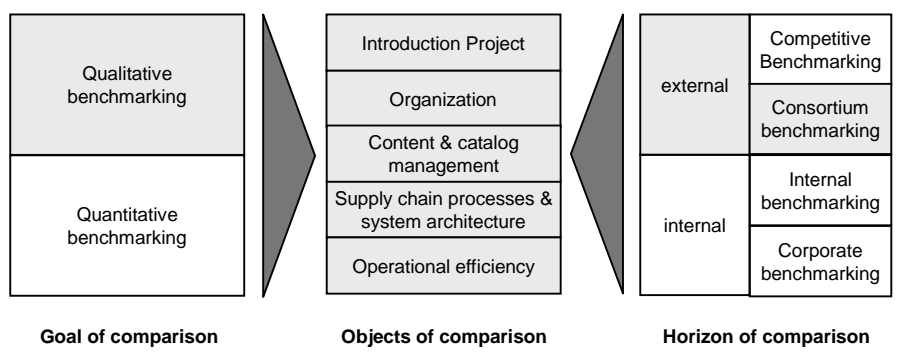

Figure 2. Focus of the benchmarking project

The benchmarking project encompassed four phases (see Figure 3). During the preparation phase objects of comparison and criteria were defined and discussed in the first consortium meeting (see Table 1). This structure was used in the questionnaires which were sent to 120 potential successful practice companies in Europe and North America. The results of the 52 questionnaires returned were reported to the consortium in the second meeting. Ten responses with the highest scores (regarding the defined criteria) were documented in more detailed case studies based on phone interviews. All cases were reported on an anonymous basis to the consortium members and prioritized during the review meeting. Finally, this assessment process led to the selection of five successful practice companies.

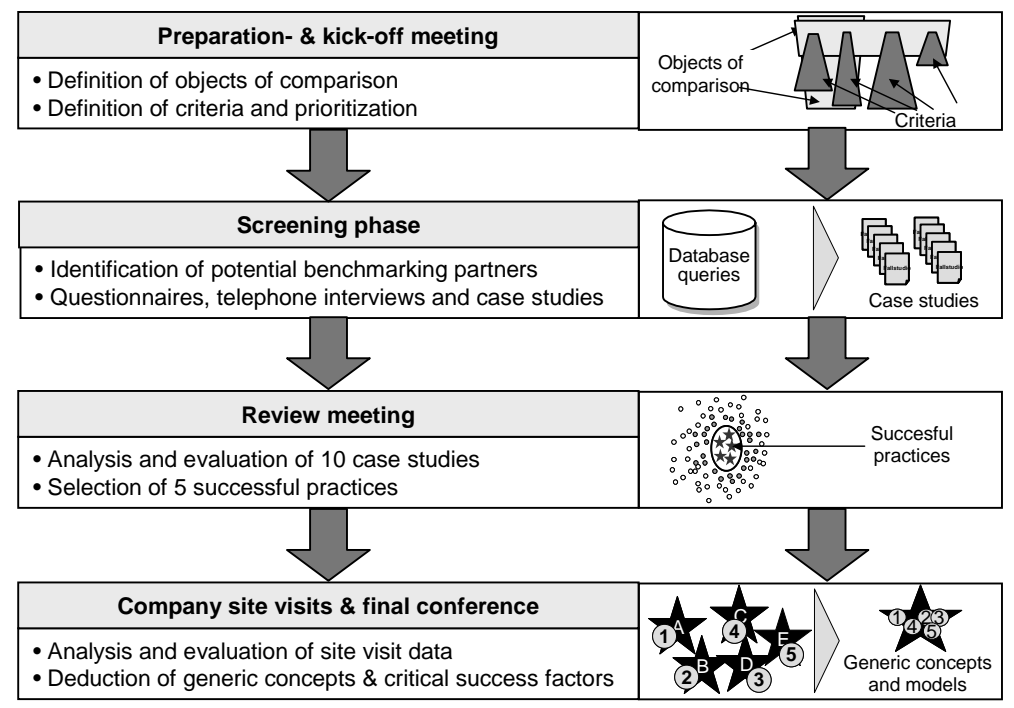

Figure 3. Research method 


\begin{tabular}{|c|c|}
\hline Object of comparison & Defined criteria \\
\hline Introduction project & $\begin{array}{l}\text { - Complete implementation of eProcurement system } \\
\text { - } \quad \text { eProcurement in operation }>\text { six months } \\
\text { - Change management system in place } \\
\end{array}$ \\
\hline Organization & $\begin{array}{l}\text { - Multi-national enterprises with large procurement volume } \\
\text { - } \quad \text { High degree of implementation } \\
\text { - Reorganization project as part of eProcurement project }\end{array}$ \\
\hline $\begin{array}{l}\text { Content and catalog } \\
\text { management }\end{array}$ & $\begin{array}{l}\text { - Criteria for the development of a procurement portfolio } \\
\text { - Company-wide product classification scheme (e.g. UN/SPSC) } \\
\text { - Use of catalog hosting on the Intranet }\end{array}$ \\
\hline $\begin{array}{l}\text { Supply chain processes \& } \\
\text { system architecture }\end{array}$ & $\begin{array}{l}\text { - Use of eProcurement standard software } \\
\text { - Internal integration with ERP systems } \\
\text { - External integration with eMarkets }\end{array}$ \\
\hline Operational efficiency & $\begin{array}{l}\text { - Measurement system for procurement (e.g. Balanced Scorecard) } \\
\text { - Use of key performance indicators } \\
\text { - } \quad \text { ROI analysis }\end{array}$ \\
\hline
\end{tabular}

Table 1. Defined criteria for successful practices

\subsection{Benchmarking partners}

The review meeting led to the selection of five successful practice companies. These companies presented their solutions during site visits. The five selected companies were:

- Babcock Borsig AG, headquartered in Oberhausen, Germany, is an international technology group operating in the fields of power engineering and shipbuilding. In keeping with its decentralized company structure, Babcock has a decentralized purchasing organization. Babcock runs a Lotus Notes-based eProcurement system which covers approx. $90 \%$ of the company's indirect procurement volume.

- Bayer $A G$, headquartered in Leverkusen, Germany, is a multi-national company with core competencies in chemical and pharmaceutical products. Prior to implementing the SAP Business-to-Business eProcurement system, Bayer started a worldwide bundling project for indirect goods in order to achieve horizontal and vertical synergies in procurement. In 2000 the company initiated an eProcurement project with an electronic catalog including some 169,000 articles from 39 suppliers.

- Cisco Systems Inc. is a manufacturer of networking equipment and services for the Internet and is headquartered in San Jose, USA. Cisco arranged its procurement in line with the different commodities the company procures (e.g. telecom, IT, training, etc.). In 1996 the company started with the implementation of the Ariba Operating Resource Management System (ORMS). Cisco purchases approx. 60\% of all indirect products and services from 17 suppliers via the Ariba solution.

- $\quad$ SAP AG, headquartered in Walldorf, Germany, is the world's largest supplier of ERP systems. The company introduced a corporate purchasing department in 1999 for the coordination of their international procurement activities. The company announced 14 purchasing managers for each country and each commodity. At the same time, the company implemented the SAP B2B Procurement system with which SAP procures approx. 16,000 items for services and IT. 
- Xerox (Europe) Ltd is headquartered in London, UK, and manufactures copiers, printers, scanners, software as well as providing services. In 1999 the company started a procurement project which focused on the reorganization of its 16 independent countrybased procurement organizations through a central commodity board that coordinates procurement on a pan-European level. Besides the procurement of indirect products, Xerox has a strong focus on the procurement of services since this represents the biggest volume in its procurement portfolio.

\section{Results of the benchmarking study}

\subsection{Introduction project}

Many large companies have a similar situation in their indirect procurement supply chain prior to the implementation of eProcurement. Little attention was paid to MRO procurement, and manual, paper-based procedures prevail. Not only are they labor-intensive and harbor a considerable error potential, but many transactions simply bypass the purchasing department and are carried out directly with local suppliers. Especially the large benchmarking companies started eProcurement with organizational concepts on corporate level. Typically, the areas purchasing, IT and financial accounting had to be coordinated in order to define common goals. Successful eProcurement implementations included more than merely a new IT system. The benchmarking project highlights five factors for the implementation of eProcurement in large organizations (see Figure 4):

- Realignment of the purchasing operation,

- Reorganization of the procurement process,

- Preparation of catalogs offering the right amount of good-quality content,

- Embracement of suppliers at an early stage, and

- Integration of eProcurement and back-end systems.

The overall introduction of an eProcurement system typically required approximately six months. All benchmarking partners had pilot solutions in place prior to the roll-out of the system. However, addressing non-technical questions took significantly longer. Bayer, for example, needed about a year to form a global commodity coordination board which was necessary to pool volumes of certain products and services. Another year was required to establish centralized master data management, a key element for data quality in the catalog. 


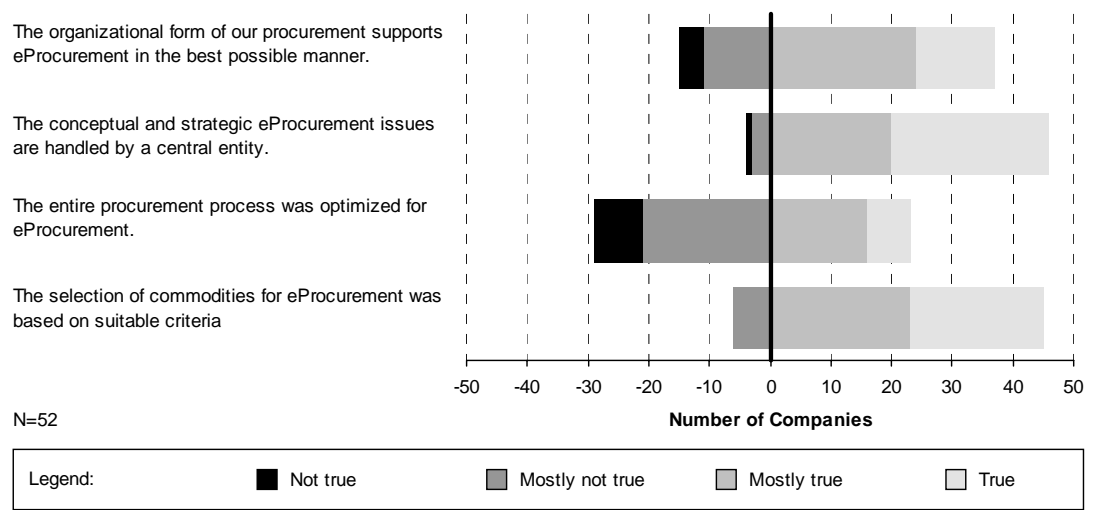

Figure 4. Implementation project

\subsection{Organization}

Prior to the introduction of eProcurement, buyers frequently had to deal with individual transactions. They had to negotiate with suppliers, convert purchase requests into purchase orders, handle queries and ensure the correct allocation of the invoices received. In the operational workload, strategic aspects were neglected and buyers had little influence over the choice of suppliers and the purchased products. Their negotiating power was limited as the purchasing decision was made by the requester or the authorizer and not by the purchasing department. The requester was at the center, with all activities emanating from him or her (see Figure 5).
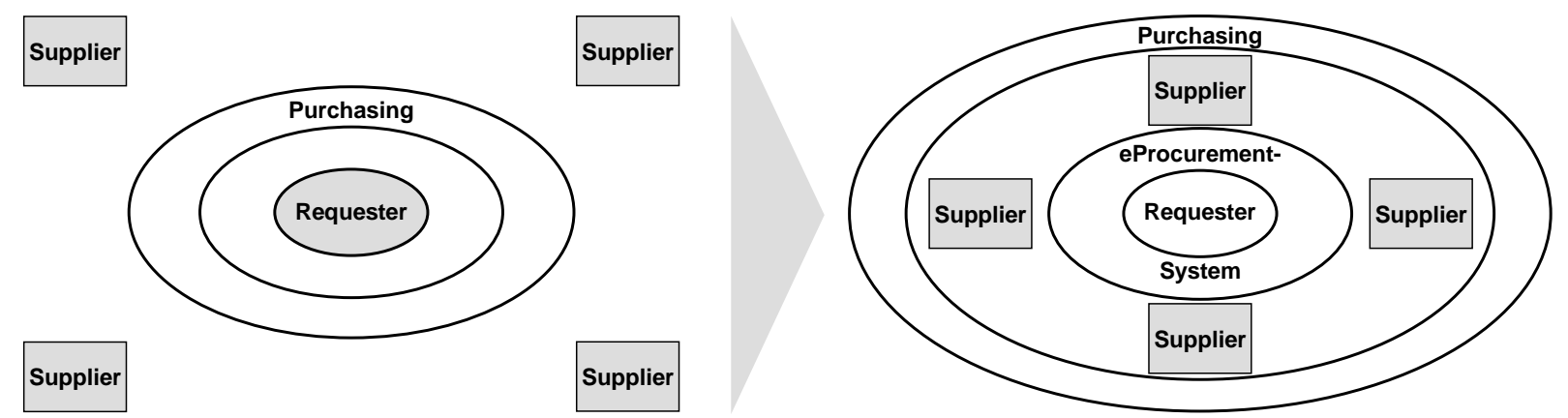

Figure 5: Shift from managing transactions to managing suppliers

eProcurement brings about important simplifications of the MRO procurement process and reduces this operational workload for buyers by decentralizing the operational procurement process. If the procurement process is to be faster and more convenient, the number of authorization stages must be radically reduced. Babcock Borsig, for example, eliminated its authorization workflow altogether. At Bayer, all employees may authorize their own purchasing operations up to a limit of EUR 1,500. SAP reduced the number of authorization stages from six to one. With the old, paper-based procurement process, numerous authorization stages were necessary and involved e.g. line and project managers, specialists or the purchasing department. Very often these people also raised objections to a lean authorization procedure. Since they have usually spent years performing the task of "authorizing", they consider it to be an important and meaningful part of their daily work. In the case of a lean procurement process, invoice verification can be simplified as well, only performed at random or replaced by a credit system. 
Supplier management is another area of organizational change. eProcurement provides the opportunity to establish preferred suppliers in the MRO area as well (Smeltzer, 2001). For this purpose it is necessary to implement supplier management as part of the eProcurement project. As most of the large companies have decentralized procurement structures in place, all of the companies analyzed implemented a central coordination instance in order to have better control over the products and services to be purchased on a company-wide basis. Bayer, for example, conducted a pooling project prior to the implementation of its eProcurement solution in order to bundle volumes on a regional and, where possible, even on a global level.

\subsection{Content and catalog management}

Despite the re-engineering of the procurement process, content management is another key factor for successful eProcurement implementation (Smeltzer, 2001; Poole and Durieux, 1999). Among our successful practice companies, four strategies were observed (see Table 2):

- Intranet catalog: Electronic multi-vendor product catalogs hosted on a company's own intranet to pool enterprise-wide demand and optimize procurement processes.

- Punchout: A catalog hosted on the supplier's website (e.g. Dell) if products are more complex and need to be configured with a product configurator.

- Auction: Auctions to leverage price reductions through supplier competition. Auctions are suitable for products and services with low complexity and allow comparison among different suppliers.

- Request for Quotation (RFQ): In settings with low frequency of use and high complexity, RFQs are an instrument for inviting suppliers to submit bids based on previously published specifications.

Identifying the right eProcurement strategy for each commodity is crucial to the success of a company's solution and therefore ranks as one of the major challenges. First of all, products and services with a very high degree of coordination effort with the supplier and a very low order frequency are certainly not candidates for eProcurement (Porter, 2001). These products require a high effort for content negotiation. Bayer, for example, conducted an auction for a plant with a value of EUR 310 million. It took the company three months to specify the product with all the necessary details in order to keep it comparable among the different suppliers. Finally, the auction was conducted with a price reduction of one percent. This confirms that when conducting auctions, price is not the sole determining factor for supplier negotiations (Kenczyk, 2001). Among the decision criteria to consider when bidding and buying engineered custom parts are quality, technical ability, cost, lead time, delivery arrangements and payment terms, to name but a few. These requirements are unique to both the part design and the capability of suppliers. Table 2 shows the criteria that characterize each single eProcurement strategy. Auctions and requests for quotations are partly complementary strategies used to reduce procurement costs. Where appropriate, companies conduct auctions for certain products and catalog them afterwards. 


\begin{tabular}{|c|c|c|c|c|}
\hline Criterion & $\begin{array}{l}\text { Intranet } \\
\text { catalog }\end{array}$ & Punchout & Auction & $\begin{array}{l}\text { Request for } \\
\text { quotation }\end{array}$ \\
\hline Number of orders & High & Medium & Low & Low \\
\hline Volume per order & Low & Low & High & High \\
\hline Number of requesters & High & Medium & Low & Low \\
\hline Number of suppliers & Low & Low & High & Medium \\
\hline Degree of standardization & High & Medium & High & Medium \\
\hline Competition & Low & Low & High & Medium \\
\hline
\end{tabular}

Table 2. Characterization of eProcurement strategies

Some companies tried to catalog services as well. In the initial phase of most eProcurement projects, services are not usually included in catalogs. However, the benchmarking study shows signs which bode well for the cataloging of services. Bayer, for example, is establishing a standard directory for maintenance services. With some 800,000 order items a year, this results in a considerable transaction volume. One item within this area, for example, is "lay one meter of cable". In collaboration with Manpower, a UK-based human resource company, Xerox has already built up a catalog for temporary staff. Function, level of qualifications, workplace and length of employment can be entered, the price is then shown and the order can be sent to Manpower electronically. Catalog orders for services are usually more detailed than paper-based orders, each item is standardized and listed individually. This makes it possible to draw an exact comparison between the invoices received and the order submitted. The main criterion for services is their degree of standardization. For example, the qualification profile of a new employee is not as standardized as a print job for a marketing brochure. Therefore, Xerox uses the punchout scenario for services with a low degree of standardization and less purchasing frequency.

Catalog management deals not with the content itself but with the physical hosting of catalogs (Dolmetsch et al., 2000). In our benchmarking study we found three different strategies (see Figure 6). An initial strategy is the use of catalogs that are hosted on a company's Intranet. The purchasing company is the owner of the catalog data and changes are typically performed by the purchasing company itself or the supplier. All the successful practices used this form of catalog hosting because the company has better control over changes and the catalog can easily be released after approval by the purchasing department. 


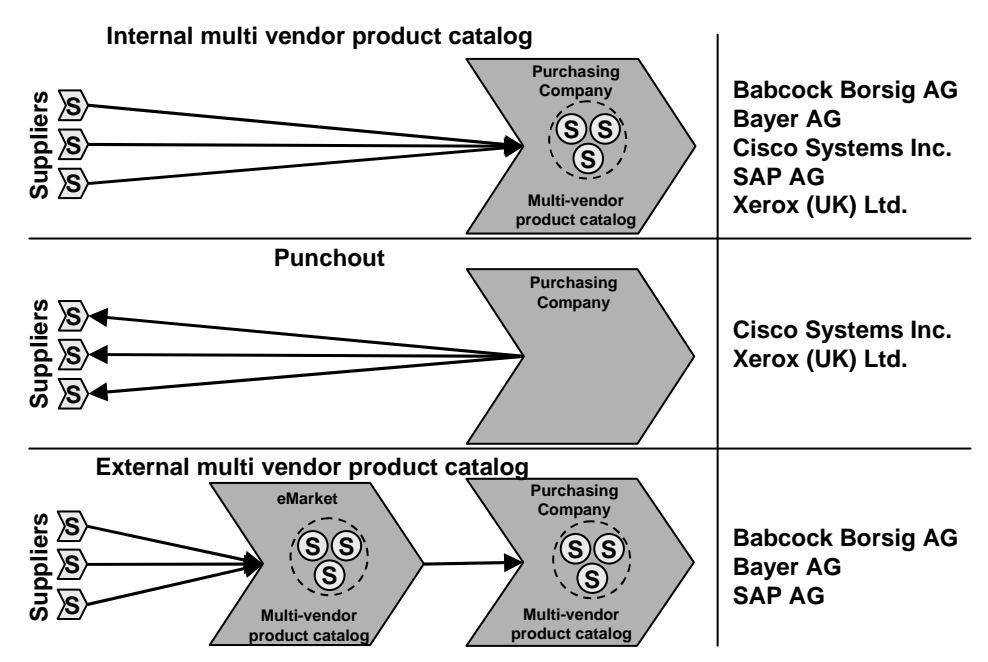

Figure 6. Strategies for catalog management

A second strategy which uses externally hosted catalogs on a supplier's website is the punchout mechanism. The punchout scenario enables requesters to access external catalogs via their own eProcurement system (Kalakota and Robinson, 2001). Selected products and services can be chosen from the supplier's electronic product catalog and transferred to the internal eProcurement system with a mouse click. The advantage of this strategy is a streamlined catalog maintenance and procurement process in the same way as the catalog would be hosted on a company's own Intranet. The requester sees only those products and services that the purchasing department negotiated. Product configurators from the suppliers that could only be integrated into a company's own Intranet with a great deal of effort are the main reason for using the punchout scenario.

A third strategy for catalog management is the use of external multi-vendor product catalogs that are hosted on electronic marketplaces. This strategy is tightly coupled with a company's general procurement strategy (Raisch, 2001). Babcock Borsig, Bayer and SAP used this strategy because they initiated their own electronic marketplaces with other partner companies. SAP, for example, introduced its marketplace emaro in order to pool volumes and standardize procurement processes with suppliers. Bayer follows the same strategy. The company launched the marketplace cc-chemplorer in October 2000 with the same 169,000 catalog items which Bayer had formerly held in its own multi-vendor product catalog. The main goal of these marketplaces was to use synergies not only within one company but also across several companies. Although a broad diffusion of these eMarkets did not occur and some solutions (e.g. emaro, EC4EC) have disappeared cc-chemplorer appears to operate successfully in the segment of outsourced content and catalog management.

\subsection{Supply chain processes and system architecture}

Compared to the internal focus of traditional logistic approaches, SCM emphasizes the management of upstream and downstream relationships and the role of supply chain optimization to increase customer value at less cost (Christopher 1998 and Ross 1998). Examples of SCM initiatives are just-in-time, zero inventory, efficient consumer response, vendor-managed inventory or continuous replenishment (Kalakota/Whinston 1997). SCM involves three areas to deal with (Klaus 1998): order processing activities, physical activities, 
and order-related financial activities. The experiences of many failed ERP implementations show that the introduction of a new system is only efficient with the redesign of existing business processes. Similarly, implementing an eProcurement system in isolation without considering the entire procurement process and the systems involved will not be sufficient (Deise et al., 2000). As shown in Figure 7, the various eProcurement strategies need to be crafted in a company's procurement process according to their strengths (Riggs and Robbins, 1998; Hughes et al., 1998; Dolmetsch et al., 2000; Kalakota and Robinson, 2001). Usually, they are complementary and support different parts of a company's procurement process.

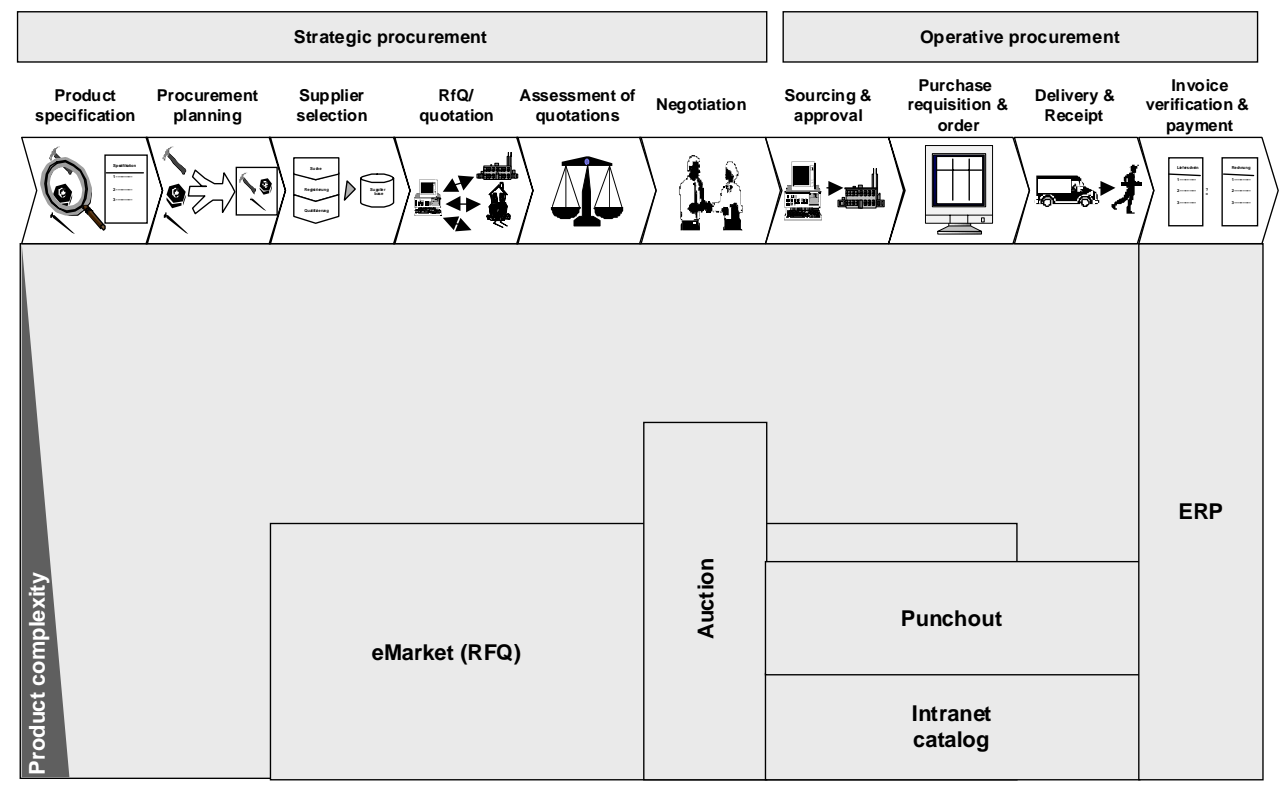

Figure 7. Supply chain processes and eProcurement strategies

At Bayer and Xerox the roll-out of the eProcurement system has been aligned with the SAP $\mathrm{R} / 3$ project. The decision in favor of a particular eProcurement system will usually depend on the existing ERP and procurement systems. However, comprehensive studies on system evaluation are not usually performed. Selecting a system tends therefore almost without exception to be a pragmatic decision. Xerox, for example, evaluated eProcurement systems from Ariba, Commerce One, Oracle and SAP, and finally chose the SAP solution because of its integration capability with their existing SAP R/3 system. Another major criterion when selecting an eProcurement system is its technological maturity. Cisco opted for Ariba's eProcurement system as it provided the best link to the Oracle system at the time and also led in terms of user friendliness. Typically, all eProcurement systems have adapters to allow seamless integration with back-end systems. Cisco's Ariba system, for example, extracts all user information such as user name, password and IP addresses from the Peoplesoft human resources system. Additional interfaces exist to link in the Oracle financial and material management system. As eProcurement is not targeted exclusively at the optimization of internal processes, integration is also required towards the suppliers and electronic marketplaces. SAP, for example, uses emaro to link with suppliers' systems for order processing and accounting. However, most of the companies still focused on internal integration whereas the link to electronic marketplaces continues to be a second priority (see Figure 9). 


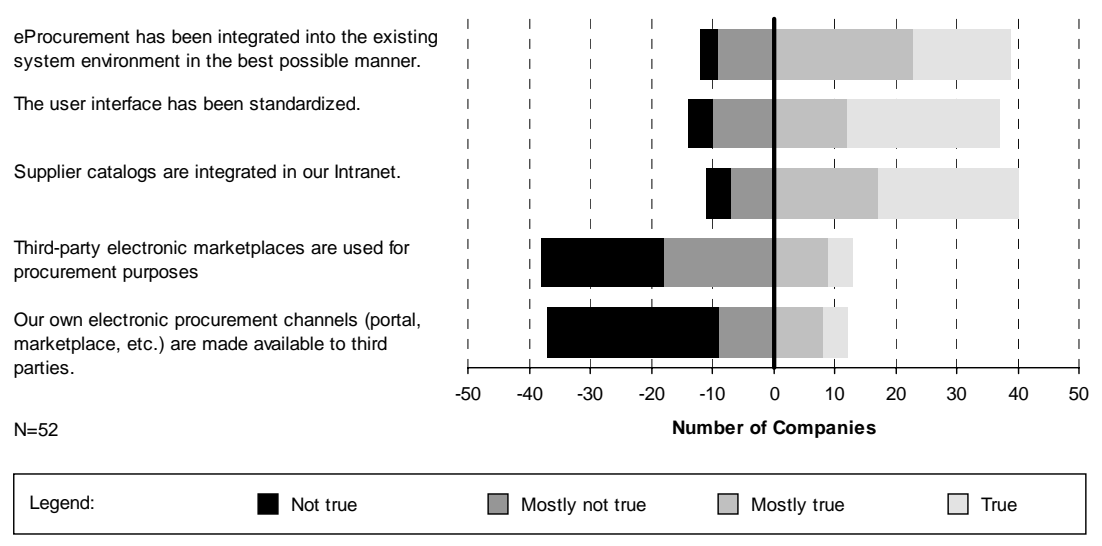

Figure 8. Use of eProcurement systems

The use of standards plays a critical role in eProcurement. Objects to be standardized are catalogs, data and processes. If the catalog data were not organized according to an ordered structure, they would be virtually unusable. For example, Bayer structured and stored its items using the eCl@ss standard (Table 3). Like UN/SPSC, eCl@ss is a product classification system. In addition, it is possible to cover various characteristics of a product with the aid of the list of attributes. Some products differ only marginally in their characteristics. A set of weighing scales, for example, may have a scale from $20-200 \mathrm{~g}$ or $10-1,000 \mathrm{~g}$ and show different graduations. However, UN/SPSC does not allow characteristics of this kind to be included.

\begin{tabular}{|c|c|c|c|c|c|c|}
\hline Company & $\begin{array}{c}\text { eProcurement } \\
\text { system }\end{array}$ & ERP system & $\begin{array}{c}\text { Catalog } \\
\text { standard }\end{array}$ & $\begin{array}{c}\text { Product } \\
\text { classification } \\
\text { standard }\end{array}$ & $\begin{array}{l}\text { Communication } \\
\text { standard }\end{array}$ & eMarket \\
\hline Babcock Borsig AG & Lotus Notes & SAP R/3 & BME-Cat & BME-Cat & ASCII & EC4EC \\
\hline Bayer AG & SAP B2B 2.0 & SAP R/3 & Harbinger & eCl@ss & $\mathrm{XML}$ & chemplorer \\
\hline Cisco Systems Inc. & Ariba Buyer 6.1 & $\begin{array}{l}\text { Oracle, } \\
\text { Peoplesoft HR }\end{array}$ & Ariba & UN/SPSC & $\mathrm{XML}$ & - \\
\hline SAP AG & SAP B2B 2.0 & SAP R/3 & Requisite & UN/SPSC & $\mathrm{XML}$ & emaro \\
\hline Xerox (OK) Ltd. & SAP B2B 2.0 & SAP R/3 & Requisite & UN/SPSC & $\mathrm{XML}$ & - \\
\hline
\end{tabular}

Table 3. eProcurement architecture components and standards

\subsection{Operational efficiency}

According to a study from (Intersearch, 1998), approx. 80\% of all purchasing transactions are spent on indirect products and services. Most Fortune 100 companies have in excess of 40,000 suppliers of indirect goods but purchase less than US\$ 10,000 annually from $80 \%$ of those suppliers. eProcurement provides an opportunity to consolidate sources and control maverick buying, which can account for dramatic savings. These cost savings are one of the most important motivations for eProcurement. Nearly all of the companies analyzed in the benchmarking study have confirmed operational efficiency. 


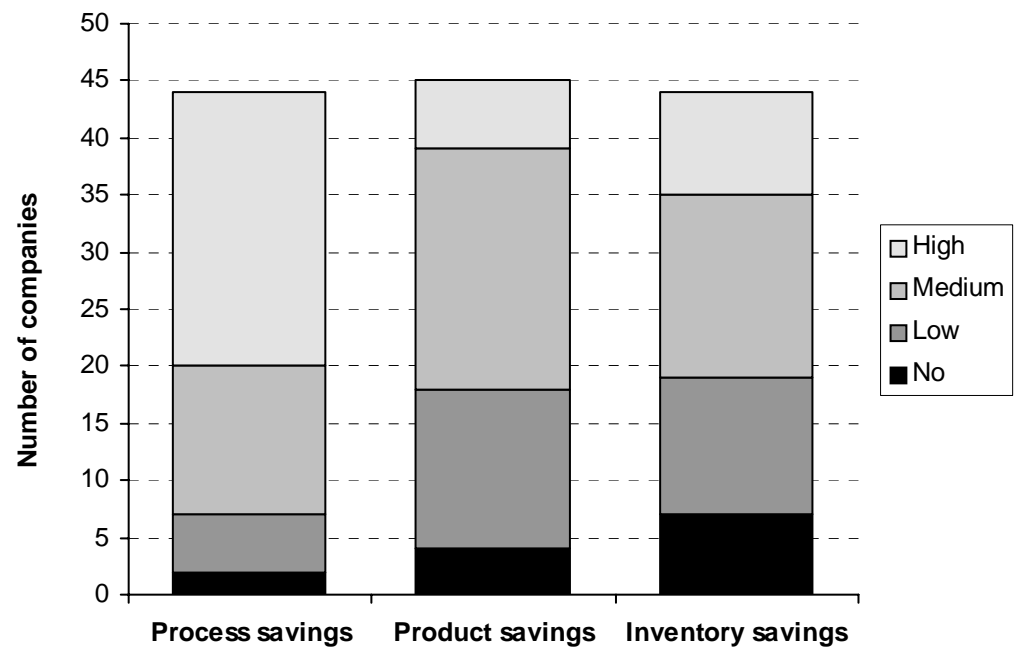

Figure 9. Savings potential of eProcurement

eProcurement benefits fall into two major categories: efficiency and effectiveness (Kalakota and Robinson, 2001). The former includes process, products and inventory savings (see Figure 9), the latter the proactive management of key data, and higher-quality purchasing decisions within organizations. Efficiency improvements are calculated on the basis of the asis situation prior to the implementation of eProcurement. The more complicated the old paperbased procurement processes, the more authorization stages and exceptions, and therefore the higher the savings will be. To take advantage of these potentials, the procurement process needs to be redesigned. In the successful practices, this redesign focused on:

- Reduction or elimination of authorization stages,

- Regulation of exceptions to a limited degree at the beginning,

- Elimination of paper,

- Integration of suppliers in the entire process chain, and

- Consideration of the complete process, from searching for articles through to invoicing.

Many figures relating to the savings potentials in the procurement process have already been published (e.g. Intersearch, 1998; Killen \& Associates, 1997). The average process costs per order in the as-is situation at all benchmarking partners lay between US\$ $70-150$. The cost reductions in an eProcurement project are on average between $50 \%-80 \%$. This savings potential, averaging US\$ 70 and more per order, forms the basis for most feasibility studies prior to eProcurement projects. The long-term eProcurement users among the benchmarking partners, namely Babcock Borsig and Cisco, confirm these savings potentials. Here, it is important to consider not only the savings in the actual purchasing operation itself but also on the part of users, authorizers, invoice verification and logistics. Cisco highlights the efficiency potential of eProcurement. In view of the company's growth structures, processes in procurement also have to grow, or be readily adaptable. Purchasing volume has more than doubled within the last two years and is nevertheless still handled by the same number of staff but now using eProcurement. 


\section{Summary and outlook}

\subsection{Summary of benchmarking results}

The benchmarking study showed that companies which successfully implemented eProcurement rely on proven concepts regarding introduction, organizational change, content and catalog management, procurement processes and system architecture in order to achieve operational efficiency. The successful practices demonstrate that eProcurement is merely a non-technical issue. The effort undertaken to implement eProcurement as a strategy is mostly spent on organizational aspects and the redesign of procurement processes rather than on technical questions. All successful practices implemented a globally oriented commodity coordination board to agree upon the products purchased via the eProcurement solution. The strong decentralization of the procurement function in large companies was a barrier to achieving synergies from pooling volumes at a corporate level. eProcurement enabled companies to gain greater transparency over their procurement portfolio with the availability of more detailed data.

The benchmarking project showed that all successful practices have strengths in certain areas. Babcock Borsig, for example, focused on the support of procurement processes in operational and strategic issues with the marketplace EC4EC that not only supported indirect but even direct procurement processes. Bayer, on the other hand, had a strong focus on content management. The company defined a high percentage of its indirect product volume and developed a catalog that also served to build up a new business segment with the marketplace cc-chemplorer. Cisco's eProcurement solution was characterized by a high degree of integration on a systems level. The young company history provides the advantage of avoiding data redundancies on a global basis. The eProcurement systems are tightly integrated with other operational systems. This allows Cisco a very high degree of transparency and standardization. The same can be said about SAP. Because of the company's IT focus, it has been using its own electronic marketplace since 1999 for the procurement of PCs from Fujitsu Siemens. The establishment of the emaro marketplace was the next step in this direction. A completely new dimension of eProcurement is provided by Xerox. The company traditionally has a strong focus on the procurement of services and it began very early with the bundling of services in catalogs.

All the companies analyzed collected know-how concerning eMarkets. But most of them did not plan to substitute their internal catalogs by catalogs hosted on eMarkets. In fact, these companies believed that electronic marketplaces complement their existing eProcurement solutions with functionality for strategic procurement issues (e.g. requests for quotations). Other companies used their internal catalogs to found eMarkets, as the examples of Babcock Borsig and Bayer show.

Table 4 summarizes the success factors which were identified in the benchmarking project and maps them against the successful practice companies. Seven independently named success factors were important in all five companies (1.2, 1.3., 2.1, 2.2, 3.3, 4.2, 5.1). Other factors can be explained by company or project specifics. The use of standards for data interchange, for example, was much more important for Bayer and SAP because these companies used eMarkets to integrate their eProcurement systems with their suppliers. This is 
the reason why these three companies also had to develop a strategy for the physical hosting of their catalogs.

\begin{tabular}{|c|c|c|c|c|c|c|}
\hline $\begin{array}{l}\text { Object of } \\
\text { comparison }\end{array}$ & Success factor & 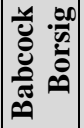 & 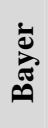 & 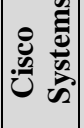 & 产 & ֻัّ \\
\hline $\begin{array}{l}\text { 1. Introduction } \\
\text { project }\end{array}$ & $\begin{array}{l}\text { 1.1 Realignment of the purchasing organization } \\
\text { 1.2 Preparation of catalogs } \\
\text { 1.3 Embracement of suppliers at an early stage }\end{array}$ & $\begin{array}{l}\bullet \\
\bullet \\
\bullet\end{array}$ & $\begin{array}{l}\bullet \\
\bullet \\
\bullet\end{array}$ & $\begin{array}{l}\bullet \\
\bullet \\
\bullet\end{array}$ & $\bullet$ & $\begin{array}{l}\bullet \\
\bullet \\
\bullet\end{array}$ \\
\hline 2. Organization & $\begin{array}{l}\text { 2.1 Automation of authorization workflow } \\
\text { 2.2 Creation of a central coordination instance for supplier management }\end{array}$ & $\bullet$ & $\bullet$ & $\bullet$ & $\bullet$ & $\bullet$ \\
\hline $\begin{array}{l}\text { 3. Content and } \\
\text { catalog } \\
\text { management }\end{array}$ & $\begin{array}{l}\text { 3.1 Identification of the right eProcurement strategy for each commodity } \\
\text { 3.2 Standardization of services for representation in the catalog } \\
\text { 3.3 Strategy for the physical hosting of the catalogs }\end{array}$ & • & • & $\bullet$ & $\bullet$ & $\bullet$ \\
\hline \begin{tabular}{l|} 
4. Supply chain \\
processes \& \\
system \\
architecture \\
\end{tabular} & $\begin{array}{l}\text { 4.1 Alignment of eProcurement strategies with the procurement process } \\
\text { 4.2 Integration of the eProcurement system with other relevant systems } \\
\text { 4.3 Use of standards for catalogs and data interchange }\end{array}$ & • & $\begin{array}{l}\bullet \\
\bullet \\
\bullet\end{array}$ & $\bullet$ & $\bullet$ & • \\
\hline $\begin{array}{l}\text { 5. Operational } \\
\text { efficiency }\end{array}$ & $\begin{array}{l}\text { 5.1 Redesign of the procurement process in order to gain efficiency } \\
\text { improvements } \\
\text { 5.2 Link to the balanced scorecard }\end{array}$ & $\bullet$ & • & • & $\bullet$ & • \\
\hline
\end{tabular}

Table 4. Summary of success factors

\subsection{Outlook}

In most companies, procurement has always been an unnoted function (Kaufmann, 1999). Management's prime interest was focused on manufacturing and sales. Recently, more and more companies have realized that procurement plays a very important role. In fact, procurement is more significant than sales in terms of its influence on company figures. For example, a case study at Mercedes-Benz identified that a $10 \%$ increase in turnover had the same effect on the operating result as a reduction in material costs of $0.518 \%$, due to the leverage effect of procurement costs (Kalakota and Robinson, 2001). Thus, eProcurement has a strategic function in most organizations as the high diffusion of (Wyld, 2004) shows. Since many companies have implemented traditional eProcurement systems, new areas of improvement come along:

- Collaborative procurement: Collaboration is aimed at a closer interaction between suppliers and customers through the use of Internet technologies such as portals. An example of such collaboration scenarios comes from the automotive industry where manufacturers report their demand and inventory status through supplier portals. These numbers are used by first-tier suppliers to feed their supply chain and production planning systems with real-time data. This form of collaboration means a two-way interaction between the manufacturer and the supplier without any manual processes.

- Mobile procurement: Adding mobile access to eProcurement applications is an option that has not yet been widely adopted. (Gebauer and Shaw, 2004) report a case study in which a field service engineer can create a purchase request for a field repair job. The application provides functionality in three areas: (1) creating purchase requisitions, (2) approving requisitions, and (3) checking the status of requisitions. Mobile procurement enhances existing eProcurement solutions and makes the application independent of the location 
where it is used. The benefits are high mobility; support for simple activities like tracking, access to ad hoc information, and reachability.

Future research can address these new areas of improvement and analyze in detail the integration of mobile and collaborative procurement functions into existing solutions. The study described in this paper was limited, because it was only a snap-shot. That's why another topic for further research is the empirical validation of the success factors which were identified in the benchmarking project. A third subject for further research can be the embedding of the success factors into procedure models for the introduction and implementation of eProcurement systems.

\section{Acknowledgements}

This research was conducted as part of the Competence Center Business Networking at the Institute of Information Management (IWI-HSG) in collaboration with the Transfer Center for Technology Management (TECTEM) at the Institute of Technology Management, University of St.Gallen. The authors would like to thank the staff from TECTEM, in particular Mr. Urs Frehner, for their cooperation and for the suggestions for revisions of the manuscript from two anonymous reviewers.

\section{References}

Aberdeen (2001), "e-Procurement: Don't Believe the Anti-Hype," Aberdeen Group, August, 29., Boston (MA).

Administration (2000), "Supplier Selection and Management Report: Most Purchasing Pros Still at the Starting Gate with e-Procurement," The Institute of Management and Administration, IOMA Inc., New York (NY).

Andersen (2001), "eProcurement: Electronic Purchasing in the German Industry - Status and Trends", Arthur Andersen Business Consulting, August, 29, Stuttgart.

Boutellier, R., Baumbach, M. and Bodmer, C. (1999), "Successful Practices in After-Sales Management", io management, Vol. 68, No. 1/2, pp 23-27.

Boynton, A.C. and Zmud, R.W. (1984), "An Assessment of Critical Success Factors", Sloan Management Review, Vol. 25, No. 4, pp. 17-27.

Camp, R. (1989), Benchmarking: The Search for Industry Best Practices that Lead to Superior Performance, ASQC Quality Press, Milwaukee (WI).

Deise, M. V., Nowikow, C., King, P. and Wright, A. (2000), Executive's Guide to E-Business: From Tactics to Strategy, John Wiley \& Sons, New York (NY).

Dolmetsch, R., Fleisch, E. and Österle, H. (2000), "Electronic Commerce in the Procurement of Indirect Goods", in: Österle, H., Fleisch, E. and Alt, R., Business Networking: Shaping Collaboration Between Enterprises, Springer, Berlin etc., pp 193-209.

Eyholzer, K. and Hunziker, D. (2000), "The Use of the Internet in Procurement", in: Hansen, H. R., Bichler, M. and Mahrer, H. (Eds.), Proceedings of the 8th European Conference of Information Systems, Vienna, pp 335-342.

Gebauer, J. and Segev, A. (1998), "Assessing Internet-based Procurement to Support the Virtual Enterprise", Electronic Journal of Organizational Virtualness, Vol. 2, No. 3, pp 30-43.

Gebauer, J. and Shaw, M. J. (2004), "Success Factors and Impacts of Mobile Business Applications: Results from a Mobile e-Procurement Study", International Journal of Electronic Commerce, Vol. 8, No. 3, pp 19-41. 
Giunipero, L. C. and Sawchuk, C. (2000), e-Purchasing Plus: Changing the Way Corporations Buy, JGC Enterprises, Goshen (NY).

Hughes, J., Ralf, M. and Michels, B. (1998), Transform Your Supply Chain: Releasing Value in Business, Thomson, London.

Industrial Distribution, (2001), "e-Procurement Still Slow to Take Off", Industrial Distribution, Vol. 90, No. 3, pp 32-34.

Intersearch (1998), National Purchasing Organisations User Group Survey, Intersearch Corp., Palo Alto (CA).

Kalakota, R. and Robinson, M. (2001), e-Business 2.0: Roadmap for Success, Addison Wesley Longman, Boston (MA).

Kaufmann, L. (1999), "Purchasing and Supply Management - A Conceptual Framework", in Kaufmann, L. and Hahn, D. (Eds.), Handbuch industrielles Beschaffungsmanagement: Internationale Konzepte - innovative Instrumente - aktuelle Praxisbeispiele Gabler, Wiesbaden, pp 3-32.

Kauffmann, R. J. and Mohtadi, H. (2004), "Proprietary and Open Systems Adoption in E-Procurement: A Risk-Augmented Transaction Cost Perspective", Journal of Management Information Systems, Vol. 21, No. 1, pp 137-166.

Kenczyk, M. (2001), "Reverse Auctions are Risky Models for Buying Custom Parts", Machine Design, Vol 73, No. 6, p 148.

Killen \& Associates (1997), "Operating Resources Management: How Enterprises Can Make Money by Reducing ORM Costs", White Paper, Killen \& Associates, Palo Alto (CA).

Lamming, R. (1995), Strategic Procurement Management in the 1990s: Concepts and Cases, Chartered Institute of Purchasing and Supply, Earlsgate Press, Stamford (CT).

Leenders, M. R. and Fearon, H. E. (1997), Purchasing and Supply Chain Management, McGraw-Hill, Boston (MA).

Monczka, R., Trent, R. and Handfield, R. (1997), Purchasing and Supply Chain Management, International Thomson Publishing, Cincinnati $(\mathrm{OH})$.

Neef, D. (2001), eProcurement: From Strategy to Implementation, Prentice Hall, Upper Saddle River (NY).

Pieske, R. (1995), Benchmarking in der Praxis: Erfolgreiches Lernen von führenden Unternehmen, Verlag Moderne Industrie, Landsberg/Lech.

Poirier, C. C. and Bauer, M. J. (2000), E-Supply Chain - Using the Internet to Revolutionize your Business, Berrett-Koehler Publishers., San Francisco (CA).

Poole, K. J. and Durieux, P. (1999), Content Management: The Critical Success Factor for eProcurement, Ernst \& Young LLP, San Francisco (CA).

Porter, M. E. (2001), "Strategy and the Internet", Harvard Business Review, Vol. 79, No. 3, pp 63-78.

Raisch, W. D. (2001), The eMarketplace: Strategies for Success in B2B eCommerce, McGraw-Hill, New York (NY).

Riggs, D. A. and Robbins, S. L. (1998), The Executive's Guide to Supply Management Strategies: Building Supply Chain Thinking Into All Business Processes, Amacom, New York (NY).

Smeltzer, L. R. (2001), "How to Build an E-Procurement Strategy", Supply Chain Management Review, Vol. 5, No. 3, pp 76-83.

Tan, C. W. and Pan S. L. (2002), "ERP Success: The Search for a Comprehensive Framework", $8^{\text {th }}$ Americas Conference on Information Systems, Dallas (TX). 
Wyld, D. C. (2004), The Weather Report for the Supply Chain: A Longitudinal Analysis of the ISM, http://www.ism.ws/ismreport/forrester, Southeastern Louisiana University, Department of Management, Hammond (CA).

Zenz, G. (1994), Purchasing and the Management of Materials, John Wiley and Sons, New York (NY). 